Archivum, LXVI, 2016, pp. 45-88

\title{
Alba del modernismo: el Parnasse francés en la literatura cubana
}

Recibido: 20/9/2016

Aceptado: 7/1/2017

\section{RESUMEN:}

A la hora de rastrear los orígenes del modernismo, la crítica literaria no ha dudado en conceder al ámbito cubano un lugar privilegiado. La razón de ello reposa en la temprana asimilación de la estética del Parnasse francés en su sistema literario. Desde la década del 1870, el parnasianismo, fuese leído directamente en francés o traducido, supuso uno de los estímulos fundacionales que llevaron a los Martí o Julián del Casal a operar un cambio radical en su concepción de la literatura. Un hecho que, si bien ha sido asumido desde antiguo por la historiografía hispánica, permanece sin embargo entre sus grandes clichés a revisar. Este artículo propone un examen atento a la presencia y relevancia del Parnasse en Cuba atendiendo a su contribución capital en el nacimiento de un nuevo orden estético y expresivo que pronto impulsaría el devenir de la poesía en lengua española hacia su contemporaneidad.

PALABRAS CLAVE: Modernismo, Fin de Siglo, Parnasianismo, Simbolismo.

The origins of Hispanic Modernism: Parnassianism in Cuban litterature

\footnotetext{
ABSTRACT:

When tracking the origins of Hispanic Modernism, Cuban literature has always been privileged by critics. This is due to the early assimilation of the French Parnasse aesthetics in its literary system. From the 1870s, Parnassianism - either read in French or translated - was one of the foundational stimuli that led Martí or Julián del Casal to change their conception of literature. This fact, in spite of being assumed by Hispanic historiography, remains as one of the main to-be-revised clichés. In this paper, a broad
} 
evaluation of the presence and relevance of the Parnasse in Cuba will be proposed, taking into account its great contribution in the birth of a new aesthetics and expressive level that inspired soon the transformation of Spanish poetry towards its contemporaneity.

KEY WORDS: Hispanic Modernism, Fin de siècle, Parnassianism, Symbolism

\section{Introducción}

Hoy en día parece no admitir ya discusión la tesis que propone la anticipación del modernismo en la zona geográfica del Caribe respecto a otros ámbitos del mundo hispánico. En el mismo sentido, la influencia del parnasianismo francés en la génesis del propio modernismo ha resultado un hecho incontestable, $a b$ initio, en la historiografía crítica sobre la materia. Sin embargo, y a pesar de todo ello, cuál no será la sorpresa de todo aquel que aborde dichas cuestiones al no hallar ningún estudio minucioso sobre la recepción del Parnaso en la literatura del Caribe -ni en ninguna otra área española-.

Este artículo se propone, pues, esclarecer en lo posible la llegada del Parnaso, de la poesía parnasiana francesa, en tanto que elemento fundacional del modernismo, a un contexto literario como el de la Cuba española, simiente donde se dio a germinar la renovación lírica de toda una literatura, la hispánica. Para ello, han sido tomados bien en cuenta los diferentes aspectos que condicionan cualquier estudio de recepción literaria. Más allá de las fuentes e influencias genéricas, formales, temáticas o estilísticas que podamos reseñar en un autor, obra o poema -aspectos que no se soslayan en ningún momento-, una parte fundamental de la documentación aportada orbita alrededor de aquellas prácticas discursivas paralelas, sean traducciones, reseñas y artículos, anónimos o firmados, aparecidas en revistas, diarios y antologías. 


\section{Revistas literarias y traducción: Antonio Sellén y la primera recepción de Gautier}

Desde la década de 1840, fueron publicándose en Cuba varias revistas como El Artista, Revista de La Habana, Brisas de Cuba, Álbum cubano de lo bueno y lo bello, etc., en cuyas páginas proliferaban las traducciones de los grandes románticos europeos: Lamartine, Byron, Victor Hugo, Leopardi, Musset... A este respecto, hay que reseñar la labor de los hermanos Francisco (1836-1907) y Antonio Sellén (1840-1889), poetas locales de aliento romántico que destacaron como ilustres traductores. Si bien el mayor, Francisco, se especializó en poesía inglesa y alemana, Antonio Sellén centró sus esfuerzos en verter al castellano a los grandes poetas franceses de su tiempo. Ya en El Kaleidoscopio (1859), revista quincenal fundada por Ramón Zambrana y Próspero Massana, el menor de los Sellén presentó "Las palomas" de Théophile Gautier, la más antigua de las adaptaciones al español de los versos de un poeta parnasiano. "Las palomas" se publicó de nuevo en la Revista Habanera (1861-1863), semanario que cedió amplio espacio a la poesía europea del romanticismo, en gran parte traducida por los hermanos Sellén y por el propio director de la revista, Juan Clemente Zenea. De naturaleza semejante a la Revista Habanera, la mensual Cuba Literaria (1861-1862) fue una de las más importantes de su tiempo. Fundada y dirigida por el poeta romántico José Fornaris y por José Socorro León, se centró, como su nombre indica, en la literatura, y conjugó de forma amena verso y prosa. Entre muchas traducciones de poetas románticos, Antonio Sellén tradujo allí otro poema de Gautier, "Elegía".

Mas no sería hasta 1883 cuando Antonio Sellén recopiló todas sus traducciones, dispersas en las revistas cubanas de su tiempo, en el volumen Ecos del Sena, selección de poesía francesa del siglo XIX. Tal como explica en su prólogo el antólogo y traductor, el objeto de la publicación parte de unos claros postulados renovadores; en primer lugar, del afán por "despertar en nuestra juventud literaria la afición al estudio de las lenguas y literaturas extranjeras, como medio seguro de ensanchar el horizonte un tanto 
limitado de nuestra naciente literatura"; y en segunda instancia, como medio de evitar "el amaneramiento, la frivolidad e insignificancia en que necesariamente ha de caer, si no se rinde culto a un ideal elevado, ni se fecunda la imaginación con el estudio y meditación de los grandes modelos que nos ofrecen las literaturas extranjeras". Junto a los grandes románticos como Hugo, Lamartine, Vigny o Musset, ampliamente representados, la antología contaba, más allá de Gautier, con muestras de la poesía de otros parnasianos como Sully-Prudhomme y François Coppée.

Pese a Antonio Sellén y sus tempranos y tímidos esfuerzos por divulgar la poesía francesa reciente, representada por los poetas del Parnasse contemporain, durante la década de los Sesenta, Setenta y primeros Ochenta el canon poético en Cuba seguía encabezado por los autores capitales del romanticismo europeo, francés sobre todo, y del realismo español. En 1865 se publicaba en La Habana una revista con el sorprendente título de Camafeos, que bien pudiera hacer pensar en alguna filiación con los Émaux et camées de Gautier o el Parnasse en general: sin embargo, el tono puramente satírico del conjunto, la pervivencia de los ecos románticos y su resistencia a contar con traducciones de literatura extranjera pronto decepcionarán a quien se acerque a sus páginas con intención de descubrir indicio alguno de modernidad. Por su parte, la Revista de Cuba (1877-1884), dirigida por José Antonio Cortina, se proponía atender a todo lo referente a la cultura en general, y pretendía estar al tanto de los movimientos intelectuales de la Europa del momento. La poesía que allí se publicó, sin embargo, era de tendencia realista y posromántica, firmada por autores menores como el propio director; y en cuanto a las traducciones, la mayoría de ellas a cargo de los hermanos Sellén, no superan en ningún caso los márgenes del romanticismo: Uhland, Vigny, Byron o Victor Hugo.

Por último, la Revista Cubana (1885-1894), dirigida por Enrique José Varona, pese a suponer una continuación natural del romanticismo de la Revista de Cuba, presentó en la sección “Notas críticas" ciertas reseñas de mayor novedad como las de Charles 
de Louvenjoul a Historie des oeuvres y a Émaux et camées de Gautier, así como sendos artículos dedicados al Parnaso: "Academia Francesa. Recepción de M. Leconte de Lisle. Discurso" de A. Dumas y "Retratos de académicos. Sully Prudhomme" de Ernest Legouvé.

\section{José Martí, renovador de la prosa y divulgador de la poesía parnasiana}

La prosa renovada y revolucionaria de José Martí (1853-1895) y el lugar que ocupa en la génesis del modernismo literario hispánico son cuestiones que han sido amplia y magistralmente examinadas por críticos de la talla de Iván Schulman, E. Anderson Imbert o Carlos Javier Morales. En concreto, el influjo del parnasianismo en la conformación de la prosa martiana, señalado parcialmente por dichos autores, goza incluso de un estudio monográfico, La sangre y el mármol. Martí, el Parnaso. Baudelaire, a cargo de la profesora Carmen Suárez León, quien ha aportado bibliografía inédita y manuscrita de incalculable valor en este sentido. Ya en época del poeta, el influjo de la prosa francesa de estirpe parnasiana en su obra llamó la atención de autores como Rubén Darío, quien en la semblanza de Martí incluida en Los raros apuntaba "su constante comunión con todo lo moderno", su "saber universal y políglota" que mezclaba "en su estilo a Saavedra Fajardo con Gautier, con Goncourt". Martí tuvo conocimiento de los autores del Parnaso desde fecha temprana: ya siendo adolescente dominaba el francés y sentía un vivo interés por el universo literario parisino. Llegó incluso a escribir algunos artículos y ensayos en un francés muy correcto. Su abanico de lecturas juveniles, puntualizadas por E. Anderson Imbert (1961, p. 96), abarca lo más granado de la prosa francesa de su siglo, si bien ello no significa forzosamente, en opinión del crítico, una influencia directa y manifiesta en su obra.

Martí había viajado a París en dos ocasiones: en 1874, tras acabar los estudios universitarios en España, y de nuevo en diciem- 
bre de 1879. Su primera visita coincidió con el éxito de las novelas escritas por los hermanos Goncourt, con Romances sans paroles de Verlaine y con las primeras exposiciones de los pintores impresionistas, de ahí que varios críticos (I. Schulman, 1974, p. 192; M. P. González, 1974, p. 225; R. Llopesa, 1989, pp. 15-24), rastreando en la prosa martiana ciertos rasgos provenientes de aquella toma de contacto, anticipen las influencias del impresionismo y del simbolismo a la del parnasianismo, asimilado únicamente tras el segundo viaje. Sin embargo, ya desde 1875 Martí estaba familiarizado con la obra de autores como Gautier y Baudelaire en su lengua original: mientras se encontraba en México, durante el bienio 1875-77, el poeta redactó una serie de notas en las que dejaba constancia de su admiración por ambos ${ }^{1}$. Y en 1879, mientras se encontraba en Madrid poco antes de cruzar los Pirineos por segunda vez, dedicó una serie de apuntes a La maja desnuda de Goya en los que trajo a colación el recuerdo de su admirado Baudelaire: "Baudelaire dijo del cuadro: les seins sont frappés de strabisme sursun et divergent. ¡Ah, Baudelaire! Escribía versos como quien con mano segura cincela en mármol blanco" (1946: I, p. 908).

Lo cierto es que fue sobre todo a raíz de su segunda estadía parisina, cuando adquirió algunas obras importantes editadas y reeditadas por la casa Lemerre, que Martí comprendió el verdadero alcance de la prosa forjada en el parnasianismo, de cuyo ejemplo comenzó a servirse para renovar la suya propia, fundamentalmente a partir del año 1881, según ya observó I. Schulman (1974, p. 88): “El quinquenio que va de 1877 [...] a 1882, es decisivo en el arte de su prosa. Durante él ensayó varios procedimientos estilísticos, se familiarizó con la gran prosa francesa de

1 En uno de los "Boletines" firmado con el pseudónimo de "Orestes" y publicado en la Revista Universal el 14 de julio de 1875, Martí alaba La Comédie de la mort de Gautier, si bien reniega de Mademoiselle de Maupin, novela que considera "insoportable" (1946: II, pp. 749-752). Y en un artículo para El Federalista, del 6 de diciembre de 1876, negaba al poeta Manuel Acuña "el arte griego de Théophile Gautier y de Baudelaire" (1946: II, pp. 629-631). 
su época y con las teorías de los parnasianos". Hubo de superar ciertas reticencias iniciales, fundamentadas en un rechazo frontal y apriorístico de los preceptos de objetividad e impasibilidad propios del Parnasse más ortodoxo. Según él mismo afirmaba, era de evitar el "amaneramiento [...] que consiste en fingir, contra lo que enseña la naturaleza, una frialdad marmórea que suele dar hermosura de mármol a lo que se escribe, pero le quita lo que el estilo debe tener [...], la lava del volcán" (apud. C. J. Morales, 1994, p. 142). Martí hallaba el gran valor del estilo parnassien en la plasticidad de la prosa de autores como Gustave Flaubert, a quien comparaba con Baudelaire y cuya Salammbô, novela parnasiana por antonomasia, adoraba sin reservas ${ }^{2}$.

A partir de 1880 comienzan a aparecer con mayor frecuencia en la obra de Martí los nombres de los autores vinculados al Parnasse contemporain. El 6 de agosto se publicaba en The Sun de Nueva York una reseña del drama Garín, de Paul Delair, en la cual aprovecha para ensalzar la libertad en el arte y no duda en comparar la obra de Delair con el "encantador Le Capitaine Fracasse de Gautier". En cuanto a la situación del teatro galo por aquellos días, afirma el cubano que "Francia (...) aguarda el momento cuando la lengua soberbia de Théophile Gautier y Charles Baudelaire se halle animado por el corazón de Corneille"(1946, pp. 850). Poco después, en el mismo diario, vuelve a referirse a Baudelaire en términos encomiásticos a través del artículo Poetas españoles contemporáneos. Martí habla allí de un momento "de transición", caracterizado por una "lucha entre la necesidad de

2 En su crónica "La última obra de Flaubert" -publicada en The Sun de Nueva York el 8 de julio de 1880-, opinaba Martí que la pluma de Flaubert "talla, cincela y modela: una pluma que saja, azota y hiere para curar mejor", y que Salammbô "es un libro tan sólido que parece hecho de mármol y coloreado con la púrpura que hizo tan famosos los países que él describe" (1973: XV, pp. 209-213). En otro texto de la misma época, "El invierno en París", publicado en La opinión Nacional de Caracas el 23 de enero de 1882, se lee: “Gustave Flaubert, que escribió, no con pluma, sino con estilo de oro, y nunca fue académico -sin que su prosa pueda compararse por lo nítida y robusta a más que a los versos de Charles Baudelaire, ni haya en la lengua de la moderna Francia cosa mejor que “Salambó" (sic)..." (1946: II, pp. 1073-1080). 
cantar y una época de turbación", que podría estar representada por la "poesía inquieta y amarga" de un Musset, de un Barbier o de Baudelaire, "almas nacidas para creer y llorar la pérdida de su fe" (1946: I, pp. 870-879). Aún sin salir de ese año, y en un texto dedicado a Raimundo Madrazo, Martí opina de él que "pintó su propio tiempo, su época", y que por lo tanto "tiene más de François Coppée que de Víctor Hugo" (1946: I, pp. 916-918).

Poco a poco, las referencias al Parnasse en la obra de Martí irán intensificándose y ganando en profundidad. En 1881 el poeta cubano se hallaba en Venezuela, donde escribió su Ismaelillo al par que redactaba y editaba la efímera Revista venezolana. En el segundo y último número de la misma, Martí publicó un importante texto teórico en defensa de una literatura de forma esmerada cuya técnica apuntaba directamente al arte pictórico: “El escritor ha de pintar como el pintor. No hay razón para que el uno use de diversos colores, y no el otro. (...) Que la sencillez sea condición recomendable, no quiere decir que se excluya del traje un elegante adorno" (2004, pp. 57-58). La transposición artística que fundamentaba la poética de José Martí por aquel entonces le hacía considerar constantemente los procedimientos y herramientas del pintor y del escultor los más aptos para auxiliar su noción del ideal literario moderno ${ }^{3}$.

Ismaelillo, su primer poemario, se editó en Nueva York en 1882, en un momento en el que Martí sentía vivo interés por la poética parnasiana y por los autores que de la misma eran partícipes. Por Carmen Suárez León (2001, pp. 99 y ss.) sabemos que en algunos cuadernos manuscritos de esa fecha, el exiliado cubano había ido proyectando varios textos de crítica literaria dedicados a autores como Leconte de Lisle, Gautier, Banville,

3 Sin abandonar este contexto venezolano, el 29 de diciembre de 1881 publicaba Martí en la "Sección Constante" de La Opinión Nacional de Caracas un breve apunte sobre el novelista ruso Iván Turguenev cuya conclusión venía a reincidir en su adhesión plena al arte de perfil escultórico de los Flaubert y los Baudelaire: "Un poeta y un novelista han tenido cincel en las manos, en vez de pluma, cuando escribían: el novelista, fue Flaubert; el poeta fue Baudelaire, genio rebelde" (1973: XXIII, p. 131). 
Catulle Mendès y François Coppée, a quien por entonces consideraba un lírico ejemplar: "Sólo en manos de Teodoro de Banville y de Catulle Mendès es el verso más flexible que en manos de Coppée". Entre diversas glosas a Les Humbles, Martí había ido intercalando su opinión sobre la maestría de Coppée en los planos estético y ético: se trata de un poeta que "odia la verbosidad odiosa, y las fáciles acumulaciones rimbombantes, -los abalorios de la poesía-. [...] Toda la poesía de la honradez [...] encaja por un arte sencillo en sus versos: y eso viene a ser Coppée, y su gran mérito -en un país de gente impura-: el poeta ve los honrados..."

Son de ese tiempo varios textos publicados en las revistas y diarios de Nueva York donde se configura la visión general que de los poetas parnasianos tuviera Martí. Una visión general de signo paradójico, aunque fundada siempre en un conocimiento cabal de la materia. El 7 de enero de 1882 firma una crónica, "El invierno de París", sobre el estado de la literatura francesa, y en particular, sobre la entrada en la Academia de Sully-Prudhomme. Al sillón del futuro Nobel aspiraban, entre otros, Catulle Mendès y François Coppée, el candidato favorito del propio Martí, el poeta que "ha escrito Le Passant y Les Humbles, y hace versos con aquella elegancia y madurez con que Cellini cincelaba copas". Del electo Sully-Prudhomme, por su parte, opinaba Martí que "es poeta tierno, grave y sincero, en quien hallan los críticos rudos excelencias tales, que juzgan que sólo las excede las del secular Víctor Hugo" (1946: II, pp. 1073-1080)

Desde su exilio neoyorquino, el maestro cubano iba dando a conocer a toda la juventud americana los nombres de la nueva poesía francesa, entonces representada por los parnasianos. Así,

4 C. Suárez (2004, p. 11) revela, por otra parte, algunos detalles de la biblioteca personal del poeta, entre cuyos volúmenes destaca un ejemplar de la obra de Paul Bourget Études et portraits (1889) cuyo capítulo dedicado a “L'esthétique du Parnas$\mathrm{se}^{\prime \prime}$ fue leído atentamente por Martí, según se colige de las anotaciones manuscritas que lo margenan. 
probablemente hubo sido el propio Martí el primer hispanoamericano en reseñar, aunque muy de pasada, la figura de José-Maria de Heredia ${ }^{5}$. El 18 de marzo de 1882 fechaba en Nueva York otra crónica dedicada a la poesía francesa, "Poetas nuevos y poetas viejos", muy favorable para con la generación parnasiana, cuya importancia radicaba, en su opinión, en haber recogido noblemente el testigo de los grandes románticos, los Hugo o Musset: " $i Q u e ́$ generación ilustre de poetas, aquella a que ahora reemplazan Coppée agraciado, (...) Mendès cincelador, Sully profundo!" (1946: II, pp. 1099-1105).

Como puede observarse, Martí no concede nunca el título de "parnasiano" a ninguno de ellos. Es más, cuando haga alguna referencia directa a la Escuela será en un tono peyorativo, negando la hipotética pertenencia a la misma de sus idolatrados jóvenes portaliras franceses. "Quincena de poetas", crónica fechada en abril de 1882, resulta bien indicativa a este respecto (1946: II, pp. 1119-1125). Allí describe un banquete en honor del flamante académico Sully-Prudhomme al que acuden los principales miembros del cenáculo parnasiano, y aprovecha de paso para reafirmarse en su concepción plástica de la poesía. Sin embargo, a propósito de los supuestos dogmas de la Escuela, no duda en matizar su punto de vista renegando plenamente de todo formalismo que no nazca supeditado al contenido, a la idea. Martí critica duramente cualquier lírica que consista en un simple artificio basado en la rima rica y el empleo de colores brillantes, "que parecen desde lejos zafiros y rubíes y perlas y esmeraldas de encantada gruta". Los artífices de esta orfebrería deslumbran-

5 En una crónica fechada el 23 de enero de 1882 declaraba que "José María de Heredia, de estirpe cubana, es poeta amado en París” (1946: II, pp. 1073-1080). Como es bien sabido, en 1893 publicó Heredia Les Trophées, y al año siguiente Martí ya mostraba su conocimiento de la obra en el artículo "Luis Baralt en París", publicado en el periódico Patria, el 8 de septiembre de 1894. En contraste con otros poetas cubanos de expresión francesa, de Heredia admitía Martí que "ya hacía versos cuando fue a París, y es acaso el que en sublime francés ha puesto más idea y color en el soneto difícil, el más breve espacio literario" (1946: II, pp. 1230-1235). 
te pero vana, los que así conciben la poesía "como dorado manto gigantesco que cubra a un pigmeillo", son precisamente los que merecen el calificativo de "parnasianos":

..Esos trabajadores del verso a quienes la idea viene arrastrada por la rima, y que extienden el verso en el papel como medida que ha de ser llenada; y en esta hendija, porque caiga majestuosamente, se encaja un vocablo pesado y luengo; y en aquella otra, porque parezca alado, le acomodan un esdrújulo ligero y arrogante. Y luego los versos suenan como agua de cascada sobre peña, muy melodiosamente; más queda de ellos lo que del agua, rota al caer, queda, y es menudo polvo. Ni ha de esforzarse la rima a obedecer mal de su grado al pensamiento, porque ni éste cabrá bien en ella, ni ella será ala buena a éste.

Martí excluye del parnasianismo a los parnasianos Mendès, Coppée, Banville -“esmaltador de la lengua, joyero delicado de la frase" - y por supuesto a Sully-Prudhomme -"no fue Sully, por de contado parnasiano, aunque trabajó mucho sus rimas"-. He aquí, por tanto, una de las grandes paradojas a las que se debe hacer frente constantemente a lo largo y ancho de los escritos martianos: la alabanza de los poetas del Parnasse contemporain junto a la condena del parnasianismo en sí. Las causas principales estriban tanto en una noción metonímica del movimiento parnasiano, atenta exclusivamente a sus aspectos más sectarios, como en la desconfianza natural del escritor hispánico ante los conceptos de escuela, grupo, corriente o cenáculo, indicio puro de modernidad si se tiene en cuenta el fuerte componente acrático consustancial al arte nuevo que entonces viene naciendo. La contradicción está servida, y Martí va dando buena cuenta de ella en aquellos años de la génesis del modernismo. Ese mismo 1882 escribía en su prólogo al "Poema del Niágara" del venezolano Pérez Bonalde que "la perfección de la forma se consigue casi siempre a costa de la perfección de la idea", condenando ahora a los cinceladores, a los poetas que gustan de situarse frente al verso "con martillo de oro y buril de plata, y enseres de 
cortar y de sajar, a mellar aquí un extremo, a fortificar allí una juntura, a abrillantar y redondear la joya [...]. Se queja el alma del verso, como maltratada, de estos golpes de cincel" (2004, pp. 59-78). Unos meses después, sin embargo, en un ensayo dedicado a Ralph Waldo Emerson, elogiaba justo por ello al escritor estadounidense: "su pluma no es pincel que diluye, sino cincel que esculpe y taja" (2004, pp. 90-106). ¿Y acaso no era por entonces Leconte de Lisle el arquetipo de poeta escultórico, el mismo a quien Martí no dudó en exaltar?

El respeto, en todo caso, dista mucho de la servidumbre, y el ideario ético y lírico del apóstol de la Independencia se situaba en las antípodas del parnasianismo puro. Ninguno de los subgéneros favorecidos por la Escuela fue cultivado por Martí: ni el poema en prosa artístico y pintoresco, de sólida formalización cimentada en la división estrófica y el estribillo, que en cambio sí sería del gusto de Darío; ni la poesía historicista, señorial e impasible, resumen de la doctrina impartida en sus tertulias por Leconte de Lisle. Idea y emoción sostienen la poética martiana. El verso artístico entendido no como un fin, sino un medio para expresar los tormentos del sujeto poético, herramienta al servicio de un ideal elevado: "Marfil en el verso, oro en el corazón",

6 En 1889 fundó Martí en Nueva York La edad de oro, revista infantil de la que tan sólo salieron cuatro números, en uno de los cuales el poeta resume para sus jóvenes lectores La Ilíada, recomendando la traducción al francés que del libro de Homero hiciera Leconte de Lisle: “El que no sepa francés, apréndalo enseguida, para que goce de toda la hermosura de aquellos tiempos en la traducción de Leconte de Lisle, que hace los versos a la antigua, como si fueran de mármol"(1995, pp. 37-49). Sobre las traducciones del griego de Leconte de Lisle, las opiniones de la crítica hispánica fueron diversas. Clarín, como Martí, se detuvo a elogiarlas: de entre las ediciones "bien traducidas" de la Odisea, citaba "por ejemplo, la francesa de Leconte de Lisle" (1895, pp. 314). Otros como Gabriel Prats y Torres (1897, pp. 516-518) fueron más severos al narrar su asistencia a una representación en París de Las Erinnias, "traducida en verso, y echada a perder, por Leconte de Lisle". Ignoraba Prats que Las Erinnias no traducía ninguna tragedia concreta de Esquilo, sino que era creación propia de Leconte de Lisle, basada en uno de los ciclos clásicos del teatro griego esquiliano, la Orestíada, y en concreto en un episodio de las Euménides. 
tal como escribió en su dedicatoria personal de un ejemplar de Versos sencillos a Manuel Gutiérrez Nájera (apud. Hauser, 1992, p. 70). Al trabajo formal Martí antepuso siempre la emoción subjetiva, y un poema como "Sed de belleza" -Versos libres- lo ilustra en toda su magnificencia: la belleza exterior, el esplendor del arte apreciado incluso superior a la propia naturaleza, carece de sentido si no proviene de la intensa expresión del yo lírico: aquel "dadme lo sumo y lo perfecto: dadme / un dibujo de Angelo: una espada / con puño de Cellini, más hermosa / que las techumbres de marfil calado / que se place en labrar naturaleza" pareciera una profesión de fe puramente parnasiana si antes no se hubiese declarado el verdadero origen de la belleza: "así por mis entrañas oprimidas / un balsámico amor y una avaricia / celeste, de hermosura se derraman".

No debe confundirse esta emoción subjetiva, humanitaria, con el excesivo sentimentalismo romántico, de índole personalista. Su postura moral rechaza de plano la trasnochada egolatría del romanticismo, pero su hondo compromiso trascendental con el ser humano lo aleja de toda torre de marfil. En este sentido, Martí seguía a su primer maestro y paternal tutor Rafael María de Mendive (1821-1886), poeta cubano de la segunda generación romántica. Mendive proponía una lírica intimista que impusiera su apacible sordina a la elocuencia y al tono declamatorio del verso que por entonces se estilaba. Pero si una novedad real trajo a Cuba la poesía de Mendive radicaba en su intensa preocupación por la forma, por la materia fónica del verso. Mediante la variedad de esquemas de entonación y la preferencia por un léxico sencillo y musical a la vez, Mendive trataba de lograr un efecto eurítmico pleno que rompiese con la monotonía de aquella dicción prefijada por las poéticas al uso que padeció gran parte de la poesía romántica escrita en español. No obstante, considerar esta búsqueda de la sonoridad versal una consecuencia de la adaptación de los preceptos del parnasianismo sería ponderar la cuestión de manera inexacta, pues Mendive se mantuvo siempre dentro de los márgenes de un posromanticismo doliente y social 
acorde con el canon poético inmediatamente anterior al desenvolvimiento de los cenáculos parnasianos ${ }^{7}$.

Esta noción de una poesía artísticamente noble pero emotiva, a la vez musical y trascendente se asemeja, más en el espíritu que en la letra, a los primeros disidentes de la ortodoxia parnasiana, cuyas obras, según se ha visto, admiraba José Martí8. Una ortodoxia de la que a veces ni siquiera él mismo pudo sustraerse, y que resuena clara en una pieza de sus Versos sencillos cuya delicada gracia parisina remite directamente al Gautier de "La Rose-thé" -Émaux et camées-: "En el alféizar calado / De la ventana moruna, / Pálido como la luna, / Medita un enamorado. // Pálida, en su canapé, / De seda tórtola y roja, / Eva, callada, deshoja / Una violeta en el té...". Aunque aislado en el conjunto de una obra poética, la suya, cuya intención comunicativa aspiraba a otras alturas, no hay duda de que se trata de un fruto del sistema literario que él mismo había estado contribuyendo a implantar. Más gananciosas fueron, en cualquier caso, las primicias de su prosa en lo que respecta a la

7 S. Salazar (1915, pp. 177-195) llegó a considerarlo una suerte de "parnasiano sui generis": "Fue un esclavo de la perfección artística [...] a la manera de Teodoro de Banville, que siendo el más triunfante corifeo de la escuela, hizo traición, con su emoción y su intensidad de sentimientos, al más caro principio de la secta: a la ausencia de todo sentimentalismo subjetivo, a la frialdad absoluta". Mendive publicó en 1848 su primer poemario, Pasionarias. En 1860 recopiló el conjunto de sus Poesías, editadas en París y en Madrid, con una tercera edición de 1883 aparecida en La Habana. Acceder a la poesía de Mendive resulta ciertamente complejo para un lector actual, a no ser en obras colectivas como Flores del siglo (1846), "galería de hombres útiles" de Cuba, o en antologías generales de poesía hispanoamericana decimonónica.

8 Más allá de Coppée o Sully-Prudhomme, C. J. Morales (1994, pp. 46-47) ha llamado la atención sobre otro de estos parnasianos menores, Henry de Cazalis, y en concreto sobre su poema "Vers dorés" por sus posibles vínculos con el ideario poético de Martí: "Accomplis ton devoir, car la beauté suprême, / Tu le sais maintenant, n'est pas celle des corps : / La statue idéale, elle dort en toi-même; / L'oeuvre d'art la plus haute est la vertu des forts". Morales ubica erróneamente el poema de Cazalis en el primer Parnasse contemporain (1866), pues el titulado "Vers dorés" que allí aparece no es otro que el homónimo firmado por Verlaine. "Vers dorés" de Cazalis pertenece a L'Illusion, obra que contó con varias ediciones aumentadas y corregidas entre 1875 y 1893. 
génesis del modernismo en lengua española, sobre todo en lo que concierne a ciertos procedimientos compositivos de índole parnasiana como la plasticidad de la descripción precisa y detallada, ajustada al tono y al tema de la composición, en una búsqueda concisa de la adecuación entre idea y forma. Martí adoptó una concepción sensorial de la literatura de una novedad radical en su contexto, mediante la cual el estilo literario debía presentar "plasticidad, y después de producirlo como poeta, se le debe juzgar y retocar como pintor: componer las distancias y valores, agrupar con concierto, concentrar los colores esenciales, desvanecer los que dañan la energía central. El estilo tiene sus leyes de dibujo y perspectiva" (apud. I. Schulman, 1974, pp. 194-195).

Uno de los textos en los que Martí pondría en práctica con mayor desenvoltura estos postulados teóricos fue su novela Amistad funesta (1885), escrita en Nueva York y publicada por entregas en el periódico Latinoamericano con el pseudónimo de "Adelaida Ral". Baste leer un fragmento del primer capítulo, en el que Martí nos describe un interior suntuoso y moderno, para cerciorarnos de su filiación a los Flaubert o Gautier:

La antesala era linda y pequeña [...]. De unos tulipanes de cristal tranzado, suspendidos en un ramo del techo por un tubo oculto entre hojas de tulipán simuladas en bronce, caía sobre la mesa de ónix la claridad anaranjada y suave de la lámpara de luz eléctrica incandescente. No había más asientos que pequeñas mecedoras de Viena, de rejilla menuda y madera negra. [...] Linda era la antesala, pintado el techo con los bordes de guirnaldas de flores silvestres, las paredes cubiertas en sus marcos de roble liso dorado, de cuadros de Madrazo y de Nittis, de Fortuny y de Pasini, grabados en Goupil; de dos en dos estaban colgados los cuadros, y entre cada dos grupos de ellos, un estantillo de ébano, lleno de libros, no más ancho que los cuadros... ${ }^{9}$

Martí, sin embargo, no redujo su prosa a este parnasianismo de transposición artística y culturalismo cosmopolita, pues supo

9 Cito por la edición moderna de Amistad funesta, rebautizada por el propio Martí con el nombre de su protagonista femenina, Lucía Jerez (2006, pp. 125-126). 
inocularle, desde temprano, sus dotes para la pintura impresionista y el psicologismo de los caracteres, aspectos que convierten Amistad funesta en un magnífico ejemplo del ideal narrativo modernista. Genio integrador, fue adoptando paulatinamente una postura sincrética en cuanto a su concepción de la prosa, emitiendo, aquí y allá, diversas observaciones que matizan sus juicios sobre el componente pictórico y escultórico de la lengua literaria. Para él nunca fue válida una división entre lo parnasiano y lo simbolista e impresionista, y abogó por una postura de absoluta libertad artística, a lo que contribuía sin duda el carácter asistemático y fragmentario de su producción. Sus ideas sobre la sensorialidad del estilo se tradujeron en un corolario epistemológico deudor de los conceptos baudelerianos de analogía y correspondencia sinestésica: "Entre los colores y los sonidos hay una gran relación. El cornetín de pistón produce sonidos amarillos; la flauta suele tener sonidos azules y anaranjados; el fagot y el violín dan sonidos de color de castaña y azul de Prusia, y el silencio, que es la ausencia de los sonidos, el color negro" (apud. I. Schulman, 1974, p. 92). Puesta en práctica en sus crónicas y artículos periodísticos diseminados por toda América, en esta noesis arraiga una de las grandes aportaciones de Martí al modernismo, mucho mayor, sin duda, que sus contribuciones a la divulgación de tal o cual autor extranjero por más imperiosa que fuese su recepción en las letras hispánicas.

\section{Aniceto Valdivia, "Conde Kostia" y la "Capillita Gauteriana”}

Personaje capital a la hora de entender la recepción en las letras cubanas y españolas de las novedades literarias francesas, Aniceto Valdivia, más conocido por su célebre pseudónimo, "Conde Kostia", pasó su infancia y adolescencia entre Cuba y España, donde fue labrándose una carrera en el mundo del periodismo y debutó como traductor y autor dramático -Senda de abrojos (1880), La muralla de hielo (1882)...-10. Tras una fugaz es-

10 El Conde Kostia es el título de una novela de Víctor Cherbuliez. Cabe seña- 
tancia en París, en 1885 regresó a Cuba con un baúl repleto de libros franceses que fue dando a conocer a los jóvenes literatos habaneros, entre ellos Julián del Casal, con quien pronto entabló una estrecha amistad, dadas las similares inclinaciones estéticas de uno y otro. El nombre del "Conde Kostia", pues, cobra cierta relevancia al haber sido el tutor de uno de los grandes modernistas como Casal en su estudio de los poetas parnasianos (vid. J. I. Gutiérrez, 1992, p. 69-84). Sin embargo, los escritos propios de Aniceto Valdivia apenas dejan constancia de la influencia del parnasianismo ni de ninguna otra corriente modernista. Valdivia "nunca sentó plaza en el modernismo -opinaba M. Henríquez Ureña (1954, p. 422)-, como si, por inexplicable paradoja, las innovaciones de forma y de ideología que admiraba en los poetas franceses no le merecieran, en lengua española, igual simpatía"11. El único poemario que he localizado de Aniceto Valdivia, Ultratumba (pequeño poema). Rimas (1879) imita a Campoamor y a Bécquer, si bien entre sus versos dispersos en la prensa de su tiempo quepa subrayar algún que otro soneto de inspiración helénica -“La Venus de Milo", verbigracia-, en el cual el autor, sin demasiada maña, parafrasea claramente a Leconte de Lisle y su "Vénus de Milo" -Poèmes antiques- ${ }^{12}$. En cuanto a su labor como

lar que dicha obra fue apareciendo por entregas en la Revista de Cuba (1877-1884), donde bien pudo el joven Valdivia haber tomado contacto por vez primera con el nombre por el que será desde entonces conocido.

11 En sus Cromitos cubanos (1892) un crítico del que en seguida se hablará, Manuel de la Cruz, no dudaba sin embargo en señalar a Gautier como el gran ascendente de la prosa del Conde Kostia: "Su lenguaje recuerda la expresión de Hugo, con más frecuencia la de Gautier [...]; es, en esfera menor, un caso análogo al de Théophile Gautier, que por sus aptitudes no pudo, aunque lo intentó con esfuerzo continuado, ir más allá de la literatura plástica, cuya perfección llevó hasta el prodigio" (1926: V, pp. 217-227).

12 Compárense, si no, los primeros versos de ambos poemas: “Marbre sacré, vêtu de force et de génie, / Déese irrésistible au port victorieux" (Leconte de Lisle); "Un milagro del genio le dio a Milo / en el candor del mármol transparente..." (Aniceto Valdivia). 
traductor, firmó una serie de Poemas de Víctor Hugo (Madrid, 1883 y 1906), otra de Yámbicos de A. Barbier (Madrid, 1885) y varias versiones sueltas de Gautier y Baudelaire en la prensa madrileña de la época ${ }^{13}$.

Por mediación de curiosos como Valdivia, en los círculos culturales cubanos iría afianzándose una predilección por la nueva literatura francesa que pronto devino casi en idolatría. La obra de los parnasianos, y sobre todo la de Gautier, gozaban por entonces de una estima altísima, a la que contribuyeron, mano a mano con Valdivia, dos figuras femeninas de alcurnia: Aurelia Castillo de González (1842-1920) y la exiliada puertorriqueña Lola Rodríguez de Tió (1843-1924). Aurelia Castillo fue una mujer muy culta, políglota e incansable viajera -en 1889 visitó la Exposición Universal de París-, autora de unas Fábulas (1878) y de una miscelánea de tono patriótico, Trozos guerreros y Apoteosis (1903), compuesta de poesías de corte neoclásico y romántico, cuentos, crónicas y ensayos. Como traductora, vertió al castellano a autores románticos y parnasianos como Coppée y Leconte de Lisle en

13 En concreto, en la revista de Manuel Reina La Diana tradujo Valdivia La Fanfarlo a lo largo de tres números, entre abril y mayo de 1882, y un drama de Gautier, Una lágrima del diablo (Misterio), entre julio y agosto de 1883. Allí vieron también la luz en 1882 varios poemas en prosa de Baudelaire, de los cuales no se especifica el traductor. Quizás las debamos al propio Valdivia... Por otra parte, en algunos dominios de internet, por ejemplo en el portal de literatura cubana www.cubaliteraria.cu, se indica que tradujo Esmaltes y Camafeos de Gautier y Ruiseñora de Catulle Mendés. No hay rastro de ambas, ni siquiera referencias mínimas, en las páginas y páginas sobre literatura hispánica consultadas. A ciencia cierta, Valdivia sí tradujo un único poema de Émaux et camées, "Humo", publicado el 6 de marzo de 1881 en Madrid cómico. De otro lado, en El Imparcial de Madrid vio la luz, el 6 de septiembre de 1880, la traducción de un "cuento humorístico" de Gautier, "De la obesidad en Literatura", firmada por unas siglas "A. V." que quizás correspondan a las de Aniceto Valdivia. Pero lo más probable es que nunca se llevasen a cabo las traducciones completas de Esmaltes y Camafeos y Ruiseñora, y se trate sólo de un error de documentación. Manuel de la Cruz, en la semblanza que dedica a Valdivia en sus Cromitos cubanos, alababa su "sentido del ritmo, y [...] si pusiera en ello el debido empeño, podría regalar a la literatura cubana un museo de camafeos y esmaltes". Y unas líneas adelante, de la Cruz lanzaba un órdago a Valdivia, instigándole a traducir los Esmaltes y Camafeos de Gautier (126: V, pp. 217-227). Quizás aquí radique el origen del hipotético error. 
fecha muy temprana $(1885)^{14}$. Por su parte, Lola Rodríguez publicó los poemarios Mis cantares (1876), Claros y nieblas (1885) y Mi libro de Cuba (1893) cuyos versos, de tendencia cívica y sentimentalismo postromántico, no recogen huella alguna del Parnaso, por más que Aniceto Valdivia, en el "Pórtico" que escribió para Mi libro de Cuba, los compare con "las finas metopas, los gráciles frisos y las ideales líneas" del Partenón ateniense, o llegue incluso a afirmar que "así como Gautier era oriental, Víctor Hugo español, y Heine francés, Lola es griega". Fue ella la encargada de presidir en La Habana, hacia 1893, el salón literario conocido como la "Capillita Gauteriana", frecuentado, entre otros, por sus amigos Aniceto Valdivia y la propia Aurelia Castillo. Allí, amén de solazarse en jornadas interminables con la lectura de poesía francesa, se organizaban certámenes para premiar la mejor traducción de alguna pieza de Théophile Gautier.

Por último, otro miembro importante de este singular cenáculo fue el crítico Manuel de la Cruz (1861-1896), revolucionario y amigo personal de Valdivia, Castillo, Julián del Casal y del propio José Martí. Su importancia para la recepción del Parnaso en Cuba estriba en un tempranero estudio sobre José-Maria de Heredia, a quien consideraba paisano de pleno derecho, interca-

14 "A Italia", de Leconte de Lisle, está fechado en "La Habana, 8 de marzo de 1885" (1914: V, pp. 423-428). Por su parte, "La primera", de Coppée, carece de datación, aunque por el lugar que ocupa en el conjunto se diría de fecha cercana a la traducción de Leconte de Lisle. Sí es seguro que, en 1892, Castillo conocía muy bien la obra del autor de Les Humbles, según da a entender en una nota dedicada al joven poeta cubano-francés E. Cornelius Price, fechada en Guanacaboa el 28 de junio de ese año (1914: III, pp. 242-259). Su apreciación positiva del Parnaso contrasta con su condena a todo lo decadente. En carta a Julián del Casal, fechada en Guanabacoa, el 3 de mayo de 1892, la autora, si bien señalaba como principales virtudes del libro Nieve las "gracias pictóricas" de sus sonetos, e incluso parafraseó su parnasianismo en los versos de "A la Maja de Casal" (1914: V, 70), no dudaba en reprocharle al joven habanero su "tributo a la moda" decadente y su afición por Joris Karl Huysmans: "Ese autor le ha hechizado con artes maléficas; (...) leer sus libros (no los conozco sino por lo que usted dice de ellos) no equivale, en mi concepto, a recibir una ducha de ideas sanas y elevadas" (1914: III, pp. 234-241). 
lado en sus Cromitos cubanos (1892) ${ }^{15}$. Tras el rotundo éxito de Les Trophées, Manuel de la Cruz refundió y amplió su ensayo, publicándolo en La Nación de Buenos Aires el 19 de marzo de 1893 y dando así a conocer el gran poemario de Heredia a una gran parte del mundo hispanohablante. El texto en cuestión atiende a diversos aspectos de la biografía herediana, principalmente a lo referente a sus raíces cubanas, al par que estudia los caracteres básicos de su obra poética. Una vez transcritos tres ejemplos del magistral arte sonetístico de Heredia -"Récif de corail", "Maris Stella" y "Les Conquérants" - y una serie de valoraciones críticas de Verlaine o Bourget, Manuel de la Cruz concluye su análisis con el siguiente esbozo de la "secta parnasiana":

Es fría, es artificiosa, [...] pero responde, sin duda, a una tendencia legítima; [...] es producto de la cultura cosmopolita de nuestra época; la audacia de esta escuela podrá no ser transformada en legado real para la posteridad, pero parece señalar la evolución última de la poesía: la idea exquisita, la emoción, intensa y viva, vaciada en forma purísima, intachable, primorosa $^{16}$.

Como puede colegirse de estas frases, de la Cruz comprendía y justificaba los principios de la Escuela, pese a no comulgar con ellos en puridad. Menos benévolo se mostraría, tal como les su-

15 No era la primera vez que citaba al gran parnasiano, pues en una polémica “Carta abierta” dirigida al español Vicente Barrantes en 1890, de la Cruz defendía el cosmopolitismo y la cultura de la isla como exclusiva "obra del esfuerzo cubano. En filosofía, Varona mantiene con gallardo brío la bandera de Varela y Luz; en España no hay quien se hombree con él. [...] José María de Heredia es el arquetipo de los parnasianos franceses. [...] ¿No se deduce de lo dicho que parecemos un pueblo nuevo y distinto de nuestros progenitores, una colonia anglo-franco-latina más bien que un vástago de la España teocrática y guerrera?" (1926: III, pp. 97-115). Por su parte, Aurelia Castillo encontraría digno de "alabanzas [...] el bosquejo biográfico de José María de Heredia" en una carta enviada a su amigo (1914: III, pp. 288-289).

16 Aún dedicaría otro ensayo posterior a "La prosa de José María de Heredia", comentando un artículo de Gastón Deschamps publicado originalmente en Le Temps. Apareció en La Habana elegante, no 23, 10 de junio de 1894 (1926: I, pp. 104-113). 
cediera a sus contertulios Valdivia o Castillo, con las tendencias más modernas, encarnadas por decadentes y simbolistas. Allá por 1895, no dudaba en afirmar que "místicos son los decadentistas y simbolistas (...) en cuyos labios la lengua se empobrece y retuerce en convulsiones epilépticas" (1926: I, pp. 136-145) ${ }^{17}$. Ese mismo año de 1895 estalla la Guerra de Independencia de Cuba, muere José Martí y la "Capillita Gauteriana" se disuelve irremediablemente con la partida al exilio de Aurelia Castillo de González, Lola Rodríguez de Tió, Aniceto Valdivia y el propio Manuel de la Cruz.

\section{El crisol de Julián del Casal y La Habana elegante}

Ajeno a los recelos contra el decadentismo propios de la "Capillita Gauteriana", Julián del Casal (1863-1893), el más joven y talentoso de su generación, vino por fin a encarnar la simbiosis del modernismo pleno en Cuba en todas sus posibilidades. Tradicionalmente, con mayores o menores matices, su poesía ha sido asociada por la crítica al parnasianismo, en gran medida para sancionar lo que allí evoca la manera de la Escuela frente a lo romántico, primero, y más tarde lo decadente o lo supuestamente simbolista (vid. J. Hernández-Miyares, 1979, p. 118) ${ }^{18}$.

17 De la Cruz detestaba el arte inmoral de los “decadentistas", como él llamaba a los modernistas. En su reseña a Nieve de Julián del Casal, valoraba este decadentismo-modernismo como una "escuela complicadísima", donde se mezclaban sin orden ni concierto influencias románticas -Hugo, Poe-, parnasianas -cita a Leconte de Lisle, a Gautier, a Baudelaire y a Flaubert-, naturalistas -Zola-, o "satanistas" -Barbey d'Aurevilly-. En su opinión, el decadentismo no era otra cosa que la consecuencia de una desviación del pesimismo secular, devenido casi en perturbación mental. De todas estas tendencias, la menos malsana sería la parnasiana, porque “los artistas del parnaso contemporáneo han depurado las adquisiciones, refrenado las tendencias y corregido todos los excesos por el buen gusto: son, en suma, como veremos en el caso típico de Heredia, los exponentes de mentes sanas en cuerpos sanos" (1926: I, p. 242).

18 Ya M. de la Cruz en 1890 y Luis G. Urbina en 1893 inauguraron esta corriente de pensamiento, luego continuada y matizada por J. Cejador (1907, p. 352), E. Horta (1908, pp. 45-57), A. Torres Rioseco (1925, p. 37) R. Blanco-Fombona (1929, p. 87), M. 
Su trayectoria poética se inicia hacia 1880, cuando pueden fecharse ciertos poemas de adolescencia imitados de los románticos europeos e hispánicos: Hugo, Leopardi, Heine, Zorrilla o Luaces $^{19}$. En 1885, como se ha dicho más arriba, trabó amistad con el "Conde Kostia" y su baúl de libros, y fue entonces cuando Julián del Casal, que ya dominaba el francés, quedó deslumbrado por la literatura parisina de los parnasianos y decadentes. Pronto quiso trasladar a su vida real el mundo de sus lecturas, transformando su pequeño cuarto en un modernísimo y artístico boudoir, ensoñado en las páginas de los Goncourt y de Gautier. Según relataba su amigo Ramón Meza, “Teófilo Gautier le seducía. No poco esfuerzo costó disuadirle de sus propósitos de salir por las calles de La Habana en piyama lujosa, recamada de oro, como aquél por las de París, en traje raro..." (apud. J. M. Monner Sans, 1952, p. 16) Su vida y sus escritos dan desde entonces un giro radical hacia lo moderno, y en este contexto, Casal colabora activamente con el gran heraldo de la nueva literatura en la isla, La Habana elegante (1883-1896). Si durante una primera época, bajo la dirección de Casimiro del Monte, la revista se caracterizaba por la inestabilidad de criterios estéticos e ideológicos $-\mathrm{La}$ Habana elegante se subtituló sucesivamente "Revista interesante para señoras y señoritas", "Semanario dedicado al bello sexo" o "Semanario artístico y literario" (vid. J. Carvajal y Belló, 1957, pp. 39-67)-, desde 1885, cuando se hizo con el timón de la publicación un amigo íntimo de Casal, J. Hernández Miyares, la revista fue abriéndose paulatinamente al modernismo. A partir de

Henríquez-Ureña (1954, p. 134), J. Lezama Lima (1941, pp. 62-97) G. Duplessis (1944, pp. 34 y 43), B. Gicovate (1962, p. 112) o L. Fontanella (1970, pp. 450-79).

19 Joaquín Lorenzo Luaces (1826-1867) fue uno de los poetas más célebres del romanticismo cubano, autor de la antología Cuba poética (1858). Destacó por sus sonetos de tema histórico y corte académico -“Bruto, primer cónsul”, "La concha de Venus", "La muerte de la Bacante"...-, que sin duda habían de preparar el terreno para la implantación en Cuba de la manera parnasiana. A este respecto J. Lezama Lima (1941, pp. 62-97) confesaba haber hojeado un libro de cuentas del padre de Julián del Casal donde el joven poeta había ido pegando recortes de periódicos y "cosas de su gusto", entre ellas "el parnasianismo inocente de los sonetos de Luaces". 
ese año se citan por vez primera en sus páginas nombres como los de Leconte de Lisle, Banville o Sully-Prudhomme, y Julián del Casal publica sus primeros textos afiliados al Arte por el arte: el relato "La felicidad y el Arte. Fantasía" (1886), o el célebre poema "Mis amores (Soneto Pompadour)" (1886), profesión de fe parnasiana bajo el signo del "Sonnet" de Gautier-La Comédie de la mort-.

Inmediatamente verán la luz sus traducciones de poemas en prosa de Catulle Mendès (1886) y Baudelaire (1887), justo antes de su frustrado viaje a París. En efecto, hacia noviembre de 1888, Julián del Casal se embarcaba con destino a la capital francesa, aunque por falta de financiación nunca pasaría de Madrid, donde parece ser que mantuvo cierta relación cordial con poetas como el malagueño Salvador Rueda o el mexicano Francisco A. de Icaza. En Madrid, ciudad que no le dejó muy grata impresión, permaneció poco tiempo, y ya en la primavera de 1889 lo tenemos de vuelta en La Habana, traduciendo a Baudelaire para La Discusión y a Mendès para otra de las revistas principales del modernismo cubano, El Fígaro (1885-1929), y dando forma al que será su primer poemario, Hojas al viento, editado en 1890. Obra transicional entre el romanticismo y el parnasianismo, las Hojas al viento de Casal revelan una fuerte impronta del Victor Hugo de Les Feuilles d'automne (1831), a cuyo tono melancólico y pesimista deben sumarse los ecos españoles de Núñez de Arce, Zorrilla o Bécquer ${ }^{20}$. Este romanticismo doliente y trasnochado alterna con traducciones y paráfrasis de Gautier -"La nube", "Las palomas"-, Coppée -“El eco", “El anhelo del monarca”- y José-Maria de Heredia -"La canción del torero"-, así como con otras composiciones propias de Casal cuyo parnasianismo revela hasta qué punto el joven cubano había ido asimilando la doctrina de tales maestros ${ }^{21}$. Amén del precitado "Soneto Pompadour", conviene

20 No está demás recordar que el poeta argentino Carlos Guido Spano había publicado en 1871 un poemario homónimo, Hojas al viento, dominado por la influencia romántica de Lamartine y veteado de poesía académica de tema helenístico. 
tener en cuenta en Hojas al viento ciertas galanterías gauterianas como "Estatua de carne", "Quimeras", "El anhelo de una rosa" o "Fatuidad póstuma", evocación de aquella "Coquetterie posthume" -Émaux et camées- cuyo filosofismo final, ausente del poema de Gautier, denota los titubeos de un poeta joven a la búsqueda de sí mismo ${ }^{22}$. En cuanto a la baudeleriana "La canción de la morfina", y como ya apuntó M. Robinson (1946, pág. 181), resulta incuestionable la intertextualidad que mantiene con el ensayo "Le Haschisch" de Les Paradis Artificiels.

Fuera de toda duda, Nieve (1892) representa uno de los hitos de la poesía parnasiana hispánica, pese a sus resabios románticos y su indudable filiación con la literatura decadente. Ya su distribución en secciones testimonia una preocupación por la arquitectura del libro propia del parnasiano en que Casal encarna

21 "La nube" remite a "Le Nuage", pieza que Gautier publicó por vez primera en febrero de 1838 en el volumen La Comédie de la mort y que ya había sido traducida anteriormente al español por M. González Prada para la Revista social de Lima (1885) y por Manuel Elzaburu para Almanaque. Aguinaldo de la Isla de Puerto Rico (1887). Por su parte, "Las palomas" hace lo propio con "Les Colombes" -en Le Figaro, 1 de febrero de 1838, luego en La Comédie de la mort-. Antes de 1890, el poema fue vertido a nuestra lengua por Antonio Sellén para El Kaleidoscopio (1859) -después en Ecos del sena (1883)-; por un traductor anónimo para El Imparcial de Madrid (1868); por R. Mayorga Rivas para El Imparcial de México (1880) o por Enrique Villar para Papel periódico ilustrado de Bogotá (1885). En cuanto a las dos versiones de Coppée -cuyos originales, "L'Écho" y "Le Pharaon", aparecieron en L'Exilée (1877)- no hemos localizado ninguna anterior a las de Casal, si bien el colombiano A. J. Restrepo incluyó después "El faraón" entre sus Poesías originales y traducciones poéticas (1899). Por último, "La canción del torero" de Heredia, primera versión española, según nos consta, del gran parnasiano cubano-francés en todo el mundo hispánico, parte de la "Chanson de Torero" que Casal leyó, probablemente, en el Supplément littéraire du Figaro del 21 de septiembre de 1889, pues las versiones que aparecieron con anterioridad no llevaban el título de "Chanson de Torero", sino el de "Redondillas" - $L a$ vie moderne, 20 de diciembre de 1879; L'Obole de la Vie moderne. Aux inondés de Murcie, 1879; Le Monde poétique, 10 de junio de 1884-.

22 La presencia gauteriana en Hojas al viento fue sugerida ya por M. Henríquez Ureña (1954, pp. 121-122): “La influencia de Gautier es la que con mayor persistencia se manifiesta en Casal, proteica y sutil, deslizándose al través de las palabras y los giros que pudieran parecer más insignificantes". 
ahora. La primera de estas secciones, "Bocetos antiguos", apunta en la dirección de Leconte de Lisle y sus Poèmes antiques y del interés común por lo plástico grato a los poetas de la Escuela. Principia con "Las oceánidas", cuya anécdota, el mito de Prometeo y su trasfondo de rebeldía, así como su estructura dialogada se ajustan a los modelos establecidos por Leconte de Lisle y por el Louis Ménard de "Prométhée délivré" -Poëmes, 1863-. La recreación objetiva de la historia y la mitología, la plasticidad descriptiva y ornamental, la ostentación léxica y culturalista y el regodeo en lo suntuoso y lo sensual continúan en el resto de composiciones: "Bajo-relieve", "La muerte de Moisés", "La agonía de Petronio" y "El camino de Damasco" siguen la pauta de la ortodoxia parnasiana.

El enfoque central de Nieve está condicionado por el profundo interés de Julián del Casal en la transposición artística y la relación poesía-pintura-escultura, según reza el título de las diferentes partes que componen el libro: "Bocetos antiguos", "Mi museo ideal”, “Cromos españoles", “Marfiles viejos". Incluso el apartado final, "La gruta del ensueño", más atento a expresar la interioridad del yo lírico, contiene varios poemas puramente plásticos como "Camafeo", "Kakemono", "Medallón" o el croquis "Al carbón". Si la plasticidad de los tres "Cromos españoles" -“Una maja”, “Un torero", “Un fraile”- engarza con la pintura romántica del Gautier de España y con el colorismo andaluz de un Manuel Reina y un Salvador Rueda, el exotismo artístico de "Kakemono" concuerda con el interés por la chinoiserie de Gautier y, sobre todo, de Louis Bouilhet, parnasiano menor de quien Casal había traducido ya en Hojas al viento la pieza "La última noche", y cuyos Festons et astragales contienen múltiples ejemplos de inspiración china, tal "Tou-Tsong" o "Le barbier de Pékin".

La segunda sección, el celebrado "Museo ideal", se integra además en la categoría de poesía ecfrástica parnasiana, una categoría privilegiada por el modernismo hispánico, abundante en muestras de innegable mérito. Julián del Casal selecciona una serie de lienzos del pintor francés Gustave Moreau (1826-1898) 
para representarlos en otros tantos poemas, y lo primero que llama la atención en este sentido no es otra cosa que la "rareza" de su elección, en contraposición con la mayoría de los poetas que en algún momento se dieron a la écfrasis, normalmente favoreciendo las obras maestras de artistas canónicos. En segundo lugar, y no menos sorprendente, resulta un hecho singular: Julián del Casal nunca estuvo en París y, por lo tanto, no pudo contemplar las obras de Moreau, sino que las conocía por reproducciones fotográficas, según testimonio de su amigo M. de la Cruz (1926: V, p. 232), y por las magníficas descripciones que J. K. Huysmans, por boca de su personaje des Esseintes, consuma en $A$ Rebours. Realmente, la pasión del poeta cubano por la pintura de Moreau nace de su "lectura" en la novela decadente por antonomasia, cuyo quinto capítulo se ocupa de "La Aparición" y "Salomé".

En cuanto a la factura de sus sonetos, Casal reconoció el magisterio de José-Maria de Heredia en una carta al propio Gustave Moreau, fechada en La Habana, el 17 de febrero de 1892 (apud. F. Morán 2010, pp. 3-4). Tras haberle hecho saber, en misiva anterior, que el mismísimo Heredia se había brindado a traducir al francés los sonetos de Nieve, Moreau recibe esta interesante confesión de Julián del Casal:

Tengo que reconocer que estoy sinceramente sorprendido al leer que deseáis que el Sr. Heredia traduzca para vos mi humilde poema. Eso me llena de orgullo, amado maestro, pero, hablando francamente, no lo merezco. El Sr. Heredia, -cuyos magistrales sonetos conozco muy bien, hasta el punto de haber intentado imitarlos, sin éxito, jay!, en "Mi Museo Ideal" - es también otro de mis dioses. Vivo de adoraciones, como otros de desdenes. Conozco de memoria su magnífico soneto "Jasón y Medea," que os dedicó. En mi primera colección de versos traduje su "Canción del torero", pero no me atreví a enviársela, porque, al releer esos versos, los hallé muy malos. ${ }^{23}$.

23 Heredia había dedicado al pintor simbolista, como acertadamente apuntaba Casal, su poema "Jason et Médée", basado en el lienzo homónimo compuesto por 
Una vez publicado Nieve, y en carta fechada en La Habana, el 20 de abril de 1892, Casal le envió a Moreau cuatro ejemplares en primicia, destinados a sus grandes maestros parisinos: al propio pintor, y luego "el segundo al Sr. Huysmans, el tercero al Sr. Heredia y el cuarto al Sr. Verlaine, si ellos pasaran algún día por vuestra residencia. Cada volumen tiene su dedicatoria". En efecto, son muchos los puntos en común entre los poemas de Casal y el patrón herediano, desde la selección léxica, temática y cromática hasta la propia estructura del soneto, con sus finales estróficos fuertemente marcados y el rotundo y evocador verso final tal como Heredia lo había aprendido de T. de Banville (1883, p. 201): "Le dernier vers du Sonnet doit contenir un trait -exquis, ou surprenant, ou excitant l'admiration par sa justesse et par sa force".

Casal abre su museo con un "Vestíbulo" donde aparece el "Retrato de Gustavo Moreau". En seguida comienza la exposición en sí, diez cuadros del artista francés que representan asuntos de las culturas hebraica y griega. A manera de díptico, los dos primeros, "Salomé" y "La aparición", son, tanto por su elegancia y sobriedad, como por haberse inspirado en los dos lienzos más célebres de Moreau, los más antologados de Julián del Casal. Aunque el referente principal sea el capítulo V de A Rebours, la figura de Salomé y la degollación de Juan Bautista contaban

Moreau en 1865, actualmente en el Musée d'Orsay de París. Por otra parte, y de nuevo en carta dirigida a Moreau, Julián del Casal pensaba que el lienzo "Perseo y Andrómeda" había inspirado a Heredia "uno de sus admirables sonetos". La serie "Persée et Andromède", incluida en Les Trophées, consta de tres sonetos, "Androméde au Monstre", "Persée et Andromède" y "Le Ravissement d'Andromède", publicados originalmente en la Revue des deux mondes el 15 de mayo de 1885. Sin embargo, a pesar de la intuición de Casal, las similitudes entre el lienzo de Moreau y estos tres sonetos de Heredia son escasas: parece más bien que el poeta cubano-francés se hubo inspirado en un poema de Banville -"Andromède", Les Exilés, 1867-, con el que mantiene indudables contactos, o en otros artistas plásticos que trataron el motivo como el Veronés, Tiziano o Puget. Moreau, además, pintó dos lienzos representando dicho motivo: "Persée et Andromède" -fechado hacia 1870, se encuentra en Bristol, City Art Gallery-, y Andromède, de fecha similar - Paris, Musée G. Moreau-. 
con una extensa tradición artística y literaria que alcanzaría su cumbre durante el Fin de Siglo: Eugenio de Castro, Henri Cazalis -quien dedicó otro díptico a Salomé en L'Illusion (1888)- y un largo etcétera que el poeta cubano bien podría haber tenido en cuenta para su configuración personal ${ }^{24}$. A continuación se presenta una serie de "trofeos" de inspiración helenística: "Prometeo" retoma el motivo ya desarrollado en "Las Oceánides", mientras que "Galatea" y "Elena" encarnan los dos arquetipos femeninos distintivos del modernismo, la mujer de pureza inviolada y la femme fatale. Elena de Troya, en concreto, fue una figura de largo recorrido en la iconografía parnasiana, y cabe destacar su presencia en los Poèmes antiques (1852) de Leconte de Lisle o en Les Princesses (1874) de Banville. "Hércules ante la hidra", "Una peri" y "Venus anadyomena" participan igualmente de los modelos parnasianos; éste último recuerda, por su tratamiento de la deidad griega del amor saliendo del mar, a un poema de Gautier, "Les Néréides" -Émaux et camées-, écfrasis a su vez de un lienzo del pintor polaco Kniatowski. Por su parte, "Júpiter y Europa" relata el célebre mito desde la óptica subversiva propia de Leconte de Lisle, según la cual el Dios todopoderoso representa una amenaza constante para el ser humano, mientras que en "Hércules y las estinfálides" pueden invocarse claras reminiscencias de "Stymphale" de Heredia. El Hércules poetizado aquí por Casal y anteriormente por Heredia, un semidiós amansado, hilando a los pies de Omphale, encarna el símbolo del principio masculino domeñado por el femenino, en una tensión dialógica de naturaleza sexual que el propio Moreau plasmó en otros lienzos como "Sanson et Dalila", y que fue del gusto de poetas parnasianos como Banville -“La Reine Omphale", Les Exilés (1867)- o Catulle Mendès -“Les Cheveux de Dalila”, Poésies (1876)-.

Si bien es cierto que la publicación de Nieve (1892) había precedido a la de Les Trophées (1893), tan sólo seis de los sonetos

24 Existe una amplia bibliografía sobre dicho motivo y su reflejo particular en la época finisecular y en la obra de Julián del Casal. Remitimos al interesado a Faurie (1966: cap. IV) Gicovate (1962: cap. V) o Primo Cano (2010: 129-180). 
que Heredia incluía en el libro eran completamente inéditos. El resto había venido publicándose, desde décadas anteriores, en revistas y antologías de gran renombre: L'Artiste, la Revue bleue, la Revue des deux-Mondes, las tres ediciones del Parnasse Contemporain, la distinguida Anthologie des poètes français du XIX siècle (1888) de A. Lemerre... Julián del Casal, recordemos, dominaba perfectamente el francés, y como cualquier poeta que de moderno se preciara es obvio que tendría acceso a toda esta serie de publicaciones. Por otra parte, no debemos obliterar la posibilidad de que Gustave Moreau se hubiese inspirado directamente en algunos sonetos de Heredia para componer sus pinturas y que, por lo tanto, ciertas analogías entre Heredia y Julián del Casal se deban, también, a este hecho, y no sólo a la lectura reiterada de Heredia que Casal reconocía.

Finalmente, "Sueño de gloria. Apoteosis de Gustavo Moreau" cierra este "Museo ideal" con una visión simbólica en la cual se representa al pintor, entre un coro de ángeles, desposando a Helena de Troya con la bendición de Dios omnipotente. Para los dos últimos apartados del libro, “Marfiles viejos" y "La gruta del ensueño", Julián del Casal recupera la entonación subjetiva y elegíaca de su ópera prima, modificada ahora por la patente lectura de Baudelaire y el "Spleen et ideal". El último poema de Nieve, "Horridum somnium", consiste en un récit de rêve de técnica parnasiana, en la transcripción de una pesadilla cuyas deudas con "Une Charogne" de Baudelaire son innegables. Sin embargo, Casal sólo tomó del genio parisino lo más circunstancial y accesorio de su poesía, y es cierto que en ningún momento logró aprehender aquellas novedades que anunciaban el simbolismo y habrían de configurar lo más esencial de la poesía moderna (vid. Berger, 1946, p. 187; J. M. Monner Sans, 1952, p. 73; B. Gicovate, 1960, pp. 119-125,).

Desde el epígrafe que lo encabeza, una estrofa de "Bénédiction" de Baudelaire, la huella del decadentismo y de Les Fleurs du mal resalta aún más acusada en el último poemario de Casal, Bustos y rimas, que vio la luz póstumamente en 1893. Dividido 
en una sección de prosas -"Bustos"- que recrean la manera de Catulle Mendès y la de Baudelaire, y otra de versos -"Rimas"-, el tono dominante del libro vuelve a ser el elegíaco, fundamentado en la expresión de la doliente intimidad del yo lírico. La misantropía, el torremarfilismo, la soledad del poeta en un ambiente hostil arraigan en una tradición secular que parte del romanticismo y deviene en clave lírica con los parnasianos, decadentes y simbolistas, desde Poe y Vigny hasta Banville, Leconte de Lisle, Gautier, Sully-Prudhomme y por encima de todos Baudelaire. El abanico de influencias, por tanto, es más amplio y complejo en este último libro de Casal. Así, un poema como "Cuerpo y alma" remite tanto a "Corps et âme" de Sully- Prudhomme -Les solitudes- como a las rarezas anímicas de Baudelaire y los decadentes. Y la composición titulada "Neurosis", por ejemplo, presenta cierto decorativismo exquisito que enlaza tanto con Gautier -"Chinoiserie", "Sonnet"- como con sus seguidores en Hispanoamérica, Rubén Darío -“De invierno"- o Manuel Gutiérrez Nájera -“La duquesa Job"-. La huella de $A z u l . .$. en los últimos poemas de Julián del Casal es innegable, mientras que Gutiérrez Nájera se había servido de las mismas sextinas isométricas que Casal pone en liza en "Neurosis" en varias composiciones de los años ochenta. Una forma métrica ésta que, por otra parte, venía siendo empleada por los Gautier -“Le Thermodon"-, Banville -en varias de sus Cariatides- o Sully-Prudhomme -"Inconstance", "Si je pouvais", "Le zénith" o "Les chercheurs"-25.

Pero si el parnasianismo ortodoxo pervive en algunas composiciones de Bustos y rimas -"Crepuscular", "Marina", "Medieval”,

25 Una de las novedades de Bustos y rimas respecto a la anterior poesía casaliana consiste precisamente en la variedad de su versificación, en el empleo de un amplio elenco de formas métricas, muchas de ellas provenientes del Parnaso. Así, "Nostalgias", por ejemplo, presenta las mismas sextinas octosílabas y tetrasílabas de "La bonne soirée" de Gautier, mientras que los cuatro rondeles que aquí aparecen -los tres titulados así, "Rondeles", y "Vieja historia"-, siguen la manera del Banville de Rondels (1875). Casal también incorpora por vez primera a su poesía el eneasílabo -“Hortensia al monte"-, el terceto monorrimo -“En el campo"-, o el verso-estribillo de raigambre baudelairiana -"Canas"-. 
"La cólera del infante" o "Sourimono"-, hablar de una asimilación del simbolismo moderno en la poesía de Julián del Casal resulta ciertamente complicado. Según afirmaba tajantemente G. Duplessis (1944, p. 153), "Casal no sabe sugerir", y su estilo es siempre definido, vigoroso, explícito, denotativo, parnasiano, en suma; una tara que el mismísimo Paul Verlaine se encargaría de reprenderle al poeta cubano en una célebre misiva:

El talento de Julián del Casal [...] es un talento sólido y fresco, pero mal educado. [...] Estoy seguro de que los poetas que más han influido en él son mis viejos amigos los parnasianos. Eso se ve fácilmente en todas las páginas de Nieve, y especialmente en los Cuadros de Moreau y en Cromos españoles. Su factura, como la de ellos, es preciosa, pero demasiado igual... ${ }^{26}$

Julián del Casal murió joven, soñando con el París de los parnasianos y los primeros decadentes, sin haber gozado del tiempo necesario para adquirir una percepción adecuada de todas las novedades poéticas que traía Baudelaire y que los simbolistas se encargarían de recoger y consagrar a la modernidad ${ }^{27}$. En tanto, y una vez superada su etapa de fusión con la revista La América, que la llevó a ser rebautizada como La Habana literaria (1891-93), La Habana elegante se convertía, a partir de enero de 1893, en el

26 Rubén Darío transcribió la carta de Verlaine en unas páginas que envió al director de La Habana elegante, Hernández Miyares, cuando supo la muerte de Casal, y que se publicaron en dicha revista el 17 de junio de 1894 (apud. M. Henríquez Ureña, 1954, p. 124).

27 En "La última ilusión", fantasía en prosa publicada en La Habana elegante el 29 de enero de 1893, luego incluida en Bustos y rimas, Casal apuntala la percepción que de París y, por ende, de la literatura moderna mantuvo hasta poco antes de su muerte: "El París raro, exótico, delicado, sensitivo, brillante y artificial; (...) el París de las heroínas admirablemente perversas de Catulle Mendès y René Maizeroy; (...) el París que visita en los hospitales al poeta Paul Verlaine; (...) el París que erige estatuas a Baudelaire y a Barbey d'Aurevilly; (...) el París que comprende a Huysmans e inspira las crónicas de Jean Lorrain; el París que se embriaga con la poesía de Leconte de Lisle y de Stéphane Mallarmé...". 
gran portaestandarte del modernismo en Cuba, acogiendo a lo más granado de la nueva literatura hispánica: Rubén Darío, Gutiérrez Nájera, José Santos Chocano, Salvador Rueda, Enrique Gómez Carrillo... En sus páginas fueron traducidos un considerable número de textos de Mendès y Coppée, especialmente cuentos parisinos, elegantes y frívolos, al mismo tiempo que eran elogiados encarecidamente los sonetos del "paisano" JoséMaria de Heredia. En fin, su sección de "Retratos", dedicados a figuras literarias francesas como Loti, Richepin, los Goncourt, Zola o Coppée, sirvieron de rico venero en la conformación de un idearium modernista justo en el epicentro geográfico de la naciente modernidad literaria.

\section{Dos cubanos en el Parnasse francés: A. de Armas y E. C. Price}

Aunque nacido y educado en La Habana, Augusto de Armas (1869-1893) escribió la práctica totalidad de su obra en francés. En 1888, con tan sólo 19 años y una breve pero intensa experiencia periodística en La Habana elegante y El Fígaro, Armas se trasladó a París, donde colaboró con periódicos como América en París y L'Echo de France. Pronto se granjeó la amistad de los poetas parnasianos de mayor renombre, y gracias a su desinteresado apoyo publicó en 1891 el que sería su único poemario: Rimes byzantines (vid. R. Darío, 1998, pp. 157-161; 1918, pp. 15-17). En el "Préface" que antepuso a su ópera prima, Augusto de Armas justificaba su elección lingüística por su amor al estudio de la lengua y la literatura galas, incidiendo en una captatio benevolentia cuyo principal destinatario era nada menos que el maestro Théodore de Banville:

Le maître Théodore de Banville a dit "que nul étranger ne fera jamais un vers français que ait le sens commun". Si donc il y a dans ce recueil quelques pièces ayant un soupçon de sens commun, peut-être voudra-t-on lui témoigner un peu de bienveillance et lui trouver un mérite relatif: ce sont là tous les éloges que l'auteur de ce livre ose espérer. 
Desde el mismo prefacio, Rimes byzantines muestra a las claras su filiación con la Escuela parnasiana. Es digna de reseñarse, por encima de otras, la influencia de Sully Prudhomme, a quien se dedica la obra con un "A mon cher maître", si bien pueden rastrearse allí las huellas de la mayoría de los principales parnasianos, a quienes se homenajea en múltiples paratextos, citas, paráfrasis e imitaciones de todo tipo: Heredia -"Hercule au Bucher", "Marsyas"-, Leconte de Lisle -“Conseil stoïque"-, Banville -“Le laurier fulmine", "Sonatine en e muet", "Gongorine"-, Gautier -“Boudoir mort", "Tercia rima"-, Mendès -"Portrait de femme", "Cauchemar"-, o Baudelaire -“Temple intime", "Hymne a l'orgueil"-. Como sucedía con el propio Julián del Casal, Armas apenas asimila, sino con rasgos muy superficiales, el simbolismo de un Verlaine, un Mallarmé o un Moréas (vid. M. Henríquez Ureña, 1941, pp. 301-344). Sin embargo, y a pesar de identificarse en varios textos con el rigor y la impasibilidad parnasianos -“Impassibilité", "Decorum"-, Augusto de Armas tiene bien poco de impasible. Poeta de espíritu angustiado, como el propio Sully-Prudhomme, dejó una cantidad nada desdeñable de composiciones -"Prophétie", "Justice" o "Regret" - en las que asoma la voz doliente del filósofo comprometido con lo trascendental entrevisto en lo cotidiano. Ello, sin embargo, no es razón para negar la maestría del cubano en tanto epígono integrador de las múltiples facetas del parnasianismo. Su poesía, como la de un Catulle Mendès, participa de lo libresco, lo imitativo, y si nunca alcanza altas cotas de lirismo, no deja en ningún momento de mostrarse correcta. Conservador, como buen parnasiano, en cuanto a métrica se refiere, abundan en estas Rimes byzantines los juegos de versificación y la metapoesía -“La Rime", "Les Syllabes", "A 1'alexandrin" o "Le Sonnet"-, un universo cuya poeticidad participa de un estado previo a la modernidad literaria plena.

La recepción de Rimes byzantines en el mundo hispánico fue escasa pero de cierta relevancia. José Martí les dedicó algunas 
palabras elogiosas en un artículo de $1894^{28 ;}$ pero fue Rubén Darío quien las dio a conocer al resto del continente americano a través del capítulo que les dedicó en Los raros. Hermanando la poesía de Armas con la de Banville, el genio nicaragüense revelaba el origen del "Préface" de Rimes byzantines:

¡Banville! Pocos días antes de morir aquel maestro maravilloso y encantador, recibió un libro de versos [Rimes byzantines]. Leyó las rimas cinceladas de Armas, y entonces le escribió una carta llena de aliento y entusiasmo. Théodore de Banville había escrito, a propósito de Wagner, estas palabras: [...] "nul étranger en fera jamais un vers français que ait le sens commun". [...] Ciertamente, le escribió el gran poeta a Augusto de Armas: -"He dicho eso, pero huélgome de confesar que vos sois la excepción de lo que afirmé".

En su escrito, Darío separa a los poetas "extranjeros" que ensayaron una poesía en francés en dos tipos: quienes nunca lograron alcanzar altas cotas de calidad -Menéndez Pelayo, Longfellow o Swinburne-, y quienes por el contrario sí lo lograron como Heredia, Moréas, Stuart Merrill, Parodi, E. C. Price o el propio Augusto de Armas, uno de esos ejemplos de poetas americanos ceñidos con "una corona hecha de ramas cortadas en el divino bosque de Ronsard". Quizás el benevolente artículo de Rubén estuviese motivado por el que Augusto de Armas le dedicase a él en fecha anterior; allí, el cubano realizaba unas interesantes declaraciones sobre el emergente genio lírico de Darío en relación con las últimas escuelas francesas y su recepción en Cuba:

Rubén Darío se juzga un decadente, por lo visto, y tanto parece agradarle ese lindo epíteto deshonrado entre nuestros literatos de la peor calaña, que cruel sería querer quitárselo. Entre los poetas castellanos es el único que yo sepa haber ensayado ritmos nuevos y

28 "Ayer fue, con su genio en la maleta, el ambicioso Augusto de Armas, y de los diez y seis a los veinte años se sentó entre Bourget y Banville, sutil como aquél y acicalado como éste, y enriqueció la lengua extraña con el iris de cristal tallado de las Rimas bizantinas" (1946, II: pp. 1777-1778). 
protestado contra la desesperante estrechez de la métrica española. No basta empero este título para enarbolar el epíteto aludido y sería conveniente renunciar a ciertas admiraciones harto pasadas de moda. Mas no seamos demasiado severos, y puesto que el medio es un dato esencial cuando se trata de juzgar un libro, ¿qué modernismo inédito podría esperarse de un país donde el poeta por excelencia es aún Víctor Hugo, el Víctor Hugo de las Orientales? Sin menoscabo de su enorme talento, Rubén Darío nos parece antes que decadente, parnasiano, y antes que parnasiano, romántico ${ }^{29 .}$

Es importante tener en cuenta que Armas, con el aire de superioridad que le confiriese su parisianismo, se refería al Darío de la segunda edición de $A z u l$, es decir, a un Darío parnasiano que no ha puesto un pie en Francia y que, por lo tanto, aún no está completamente al tanto del verdadero rumbo simbolista que la poesía francesa había tomado ya por aquellos días. Armas, sin embargo, sí se considera en el secreto, si bien ello no signifique infidelidad alguna para con los maestros de la Escuela parnasiana. Unos meses más tarde, y frente a los duros ataques que el Parnasse venía recibiendo en París, el poeta cubano se propuso romper una lanza en favor de su compatriota, maestro y amigo José-Maria de Heredia. En un artículo publicado de nuevo en $\mathrm{La}$ Habana elegante, Armas ensalza al autor de Les Trophées al par que considera lo demodé del parnasianismo, no dudando en proclamarse a sí mismo ya poeta simbolista: lo parnasiano no "responde a las exigencias del pensamiento moderno y legítimo", de un "movimiento intelectual -al cual me honro de pertenecer-", el cual "abandona los caducos moldes en busca de formas más amplias y más sugestivamente musicales" (apud. C. Suárez León, 2001, p. 38). Esta declaración bien puede dar una idea de cuál era

29 "Rubén Darío", escrito en París poco antes de la muerte de Armas y publicado en La Habana elegante el 2 de abril de 1893 (apud. C. Suárez León, 2001, p. 36-37). Sobre el posible influjo de la poesía de Armas en la de Darío, M. Henríquez Ureña (1941, pp. 301-344) señaló el parecido más que razonable entre la célebre "Sonatina" del nicaragüense y un poema de Rimes byzantines como "Gongorine": "Inès est triste - deux opales / S'éperlent sur sa joue en fleur. / Ses lèvres tremblantes et pâles / Ont perdu leur vive couleur...". 
el rumbo de la poesía de Armas tras la publicación de sus Rimes Byzantines, una poesía de naturaleza simbolista que el poeta tenía pensado agrupar bajo el título Le poème d'un cerveau y que por desgracia nunca llegaría a publicarse.

La obra de Augusto de Armas ha caído en un completo olvido, y apenas se la cita un par de veces más acá de la época modernista. Un compatriota suyo, el bohemio José Manuel Poveda, pronunció una conferencia, "Para la lectura de las Rimes byzantines", en la que, dando rienda suelta a su retórica estilizada, consideraba a Armas "entre los parnasianos, el más artífice, [...] temeroso de la vulgaridad subjetiva, satisfecho de vivir en sus sentidos, los ojos en contemplación, el oído atento, el alma loca de armonía y sumergida en sueños de estilo..." ${ }^{30}$. Finalmente, un crítico de la talla de Alfonso Reyes le dedicó un artículo, "Sobre las Rimas bizantinas de Augusto de Armas", donde calibraba el lugar que corresponde al poeta cubano en el devenir de la poesía modernista: "naturaleza mediocre $[\ldots]$ que nunca inventa, $[\ldots]$ que raras veces conmueve, aunque gusta en la mayoría de los casos; cuyos versos [...] descuellan cuando emplean los más felices recursos de la escuela" (1960: I, pp. 102-113).

Por el nombre de Edouard Cornelius Price (1870-i?) responde otro autor cubano de lengua francesa, uno de aquellos "poetas medianos" que Darío juzgaba entre los que escribieron meritoriamente en la órbita del Parnasse (1998, p. 159). Con apenas veinte años se marchó a París, no sin antes publicar en la Revista Cubana una serie de poemas escritos en castellano -"La muerte de un caballo", "Canto de pájaros"-, madurados en la estela del Coppée de Les Humbles. El propio François Coppée, con quien Price mantenía cierto contacto epistolar desde La Habana, apadrinó al joven cubano a su llegada a París, corrigió sus primeros versos en francés y lo recomendó al editor Lemerre (vid. A. Cas-

30 Rafael Estenger, en su prólogo a la edición de las prosas póstumas de Poveda, nos relata que la viuda de éste arrojó al fuego todos sus papeles, entre los cuales hallábase una traducción íntegra de Rimes byzantines (1948, pp. 39-42). 
tillo, 1914: III, p. 242). También se sabe que por intercesión de su amigo Julián del Casal, Price tuvo la oportunidad de presentarse a otros grandes artistas como el pintor Gustave Moreau ${ }^{31 .}$

En 1892, y cuando apenas han transcurrido unos meses de su llegada a la capital, la casa editorial de A. Lemerre publica el primer poemario de Price, Pour l'amour des vers, cuya agradecida dedicatoria reza así: "A mon cher maître François Coppée j' offre respectueusement ces premiers vers". Price, desde su brindis "Au lecteur", revela su adhesión al Arte por el arte -"Je fais de vers pour rien, pour le plaisir"-, si bien en la "Profession de foi" que abre la primera sección del libro confiesa ser la poesía subjetiva de talante amatorio la que goza de su mayor predilección. Se trata la suya de una lírica de tono confesional, colindante con la cursilería, sustentada en el continuo apóstrofe a una amada silenciosa, en consonancia con la manera del Coppée de las Intimités. Sin embargo, no deja de mostrarse Price un parnasiano cabal en varios pasajes del libro. Así, la sección "Amantes antiques" sigue el modelo de Les Princesses de Banville en una serie de sone-

31 Se conservan varias cartas de Casal a Moreau que así lo certifican. En una de ellas, fechada en La Habana, el 5 de marzo de 1892, se lee: “tengo el honor de presentaros al portador de estas breves líneas, el Sr. Edouard Cornelius Price, uno de mis verdaderos amigos y un gran poeta cubano-francés, como el Sr. Heredia, y que hace unos meses se estableció en París. Pronto hará su debut en las letras francesas, bajo la protección del Sr. François Coppée, con un espléndido volumen de versos. [...] Él se ha ofrecido, voluntariamente, a ir en mi nombre a vuestra residencia y a darme noticias de vuestro estado de salud...". Price, según confirma Casal en otra carta del 19 de agosto de 1892, causó una grata impresión a Moreau: "En cuanto a mi amigo, Cornelius Price, estoy feliz de saber la impresión que os hizo. Lo esperaba de antemano y por esa misma razón fue que me atreví a presentároslo...". Y en su última misiva al pintor -1 de enero de 1893-, Casal proyecta que sea Price quien traduzca sus versos al francés: "Si no puedo traduciros mis pensamientos, uno de mis amigos, el Sr. Cornelius Price, por ejemplo, os traducirá lo que yo escriba en español" (apud. F. Morán, 2010, pp. 3-4). Conviene recordar que Casal había dedicado a Price una sección de Nieve, "Gruta del ensueño", a lo que Price correspondió ofrendándole dos sonetos, "Messire la guerre" y "Ce que j'aime", imitación este último de "Mis amores" de Casal: "J'aime la nacre, les émaux, les marbres blancs, / les gemmes dans les feux de l'or qui les enchâsse, / l'infini du ciel pur et la mystique châsse, / les regards de la lune et le vol des milans...". 
tos consagrados a diversas heroínas histórico-legendarias como "Phryné", "Aspasie", "Cléopatre", "Hérodiade" o "Sappho"32, por su parte, el poema épico-narrativo que cierra la obra, "Édith au cou de cygne", concuerda en tono, temas, ambientación y versificación con el modelo de los Poèmes barbares de Leconte de Lisle $^{33}$.

\section{Conclusión: Parnasianismo en Cuba tras la Guerra de la In- dependencia}

Los sucesos del 98 dinamitaron el devenir del modernismo cubano, forzando a un replanteamiento de los esquemas literarios precedentes. Una poética del perfil del parnasianismo fue condenada al ostracismo, si bien hubo autores menores que retomaron algunos de sus rasgos en una serie de obras publicadas durante los primeros lustros del siglo XX. Entre ellos, mención especial merece Francisco Javier Pichardo (1873-1941), poeta sobrio y pulcro de achaques románticos cuyo único libro, Voces nómadas (1908), incluye traducciones de Catulle Mendès y de Heredia, así como sonetos propios -“Dánae”, "El jamelgo", el tríptico "Selva cubana" o "Tritón"- escritos bajo el signo de Les Trophées. De otra parte, hay que situar al malogrado René López (18821909) entre aquellos poetas de la segunda generación modernista cubana que siguió muy de cerca la huella de Julián del Casal. Aniceto Valdivia, "Conde Kostia”, compiló varios poemas suyos en la antología Arpas cubanas (1904), algunos de tono romántico, como "Barcos que pasan" o "Versos de orgía", y otros parnasiano: "El escultor", "Página de rosa", "Retrato" o "Cuadro anda-

32 La sección está dedicada a Aurelia Castillo de González, "maternelle amie" del poeta que correspondió traduciendo al español "Safo" y dedicándole un soneto, "A mi querido amigo Eduardo Cornelius Price" (1914: V, 57-58).

33 Aún daría Price a la imprenta un último título, Le Chariot errant (1900), al cual no he tenido acceso. Según informó M. Henríquez Ureña (1938, pp. 301-344) se trataba de "una obra teatral, poema cómico-bárbaro más para leído que para representado". 
luz", fechado en 1899 y dedicado a Salvador Rueda, indudable ascendente, junto a Casal, de López ${ }^{34}$.

Para concluir, hay que destacar entre los epígonos del último modernismo cubano a José Manuel Poveda (1888-1926), el más excesivo y alucinado de ellos. En 1905 comenzó a publicar sus primeros versos en la revista habanera El estímulo, que él mismo había fundado, y entre 1908 y 1910 colaboraba con artículos sobre autores extranjeros y traducciones en las revistas de Santiago El Pensil y Renacimiento. Gran agitador cultural de su país, fundó en 1912, en La Habana, la Sociedad de Estudios Literarios, donde impartía conferencias y fue dando a conocer su obra ensayística, sus versos y sus traducciones de parnasianos y simbolistas -Banville, Augusto de Armas, H. de Régnier, Rodenbach, Stuart Merrill...-. Por fin en 1917 Poveda hizo acopio de toda su poesía dispersa en el volumen Versos precursores, cuyo "Prefacio del autor" explica la naturaleza de las cinco secciones que conforman la obra como "períodos estéticos por los cuales atravesó sucedáneamente el yo en formación, antes de alcanzar su cima solitaria". De esta guisa, y no dudando en citar a los autores que más le influyeron en cada una de estas etapas, Poveda parte del "Joyel parnasiano" que da título a la primera sección hasta el decadentismo de "Evocaciones" y "Advocaciones" y el simbolismo de "Las visiones y los símbolos", para concluir con unos humanitarios y visionarios "Cantos neodionisíacos".

Sin duda, este "Joyel parnasiano" descuella entre los escasos ejemplos en que un autor hispánico reconoce explícitamente una producción propia con dicho epíteto, y según se afirma en el citado Prefacio, "resume las voces dispersas: canciones, poemetos (sic) de todas las jornadas, unidos por lo que tienen de común, el culto de la forma, el gusto de la plástica, la adoración de lo perfecto". Empero, la única característica común a los poemas

34 René López murió joven, a los 27 años, sin publicar poemario alguno. Su obra dispersa, que apareció en las revistas de la isla entre 1903 y 1909, ha sido compilada por Jorge Yglesias en el pequeño volumen Barcos que pasan (1986). 
que se integran en este "Joyel parnasiano" resulta del empleo del soneto, frente a la ametría del resto de secciones; además, paradójicamente es en el simbolismo y no en el parnasianismo donde abrevan realmente. La subjetividad del autor se enseñorea de cada una de las piezas, plenas de sugerencias místicas, músicas lunares, psicologismos y negras melancolías de sesgo baudelairiano. Incluso los medallones dedicados a sus autores predilectos no corresponden precisamente a los miembros del Parnasse: "Albert Samain", "Paul Verlaine", "Stéphane Mallarmé"... Si algo de estos Versos precursores se ajusta a la preceptiva de la Escuela parnasiana no se trata del "Joyel parnasiano", sino de la sección "Advocaciones", cuyas recreaciones históricas - "Casandra" o "Clytemnestra"- no desfiguran el hieratismo y el decoro herediano de Los trofeos. Poeta sincrético, poeta poliédri$\mathrm{co}$, poeta donde se recogen todas las voces y los ecos románticos, parnasianos y decadentes del crisol finisecular, Poveda encarna al cabo el amaneramiento al que debía conducir, como a un callejón sin salida, aquel modernismo mimético que ya no era siglo XIX ni acabaría de arribar tampoco a $\mathrm{XX}^{35}$.

\section{Referencias bibliográficas}

Anderson Imbert, E., (1961) Crítica interna. Madrid, Taurus.

Armas, A. DE., (1891) Rimes byzantines. Paris. Bibliothèque de "Europa y América".

Arpas cubanas. Poetas contemporáneos (1904). Prólogo de Conde Kostia. La Habana, Imp. Rambla y Bouza.

Banville, TH. DE., (1883) Petit traité de poésie française. Paris, G. Charpentier.

35 Como mera curiosidad, reseño aún una de las últimas antologías hispánicas de traducción que cuenta con poetas del Parnaso, Festín de poesía (1984), obra del cubano Samuel Feijóo. En el prólogo, que trata de cuestiones de traductología, Feijoo glosa varias versiones de sonetos de José-Maria de Heredia, para en seguida traducir algunos poemas de Baudelaire, Banville y Coppée, si bien son los poetas decadentes y simbolistas los que copan mayoritariamente el libro. 
Berger, M. R., (1946) "The influence of Baudelaire on the poetry of Julián del Casal", en The Romantic review, 37, pp. 177-87.

Blanco-Fombona, R., (1929) El modernismo y los poetas modernistas, Madrid, Mundo Latino.

Carvajal y Belló, J., (1957) "A través de La Habana Elegante", en Revista de la Biblioteca Nacional, VIII, pp. 39-67.

Casal, J. Del., (2001) Poesía completa y prosa selecta. Edición de Álvaro Salvador. Madrid, Verbum.

Castillo de González, A., (1914) Escritos de Aurelia Castillo de González y algunos de Francisco González del Hoyo / en apéndices, cartas de los señores Rafael Montoro, Manuel de la Cruz, Manuel Sanguily, Dulce María Borrero de Luján, Max Henríquez Ureña, La Habana, Imprenta El Siglo XX de Aurelio Miranda.

Cejador y Frauca, J., (1907) Cabos sueltos: Literatura y Lingüís-

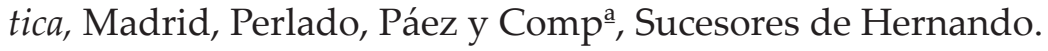

“Clarín”., (1895) “Libros viejos", en La Ilustración Ibérica, XIII, 646, pág. 314.

Cruz, M. de LA., (1926) Obras de Manuel de la Cruz, Madrid, Biblioteca Calleja.

Сива рое́тICA (1858) Colección escogida y dirigida por José Fornaris y Joaquín Luaces: La Habana, Imprenta y papelería de la Viuda de Barcina.

Darío, R., (1918) Letras. Madrid, Mundo Latino.

--(1998) Los raros. Zaragoza, Libros del Innombrable, 1998.

Duplessis, G., (1944) "Julián del Casal”, en Revista bimestre cubana, LIV, pp. 34-43.

FAURIE, M. J., (1966) Le modernisme hispano-américain et ses sources françaises. Paris, Centre de Recherches de l'Institut d'Études Hispaniques. 
Fontanella, L., (1970) "Parnassian Precept and a New Way of Seeing Casal's Museo ideal", en COMPARATIVE LITERARY STUDIES, VII, 4, pp. 450-479.

Gicovate, B., (1960) “Tradición y novedad en un poema de Julián del Casal", en Nueva Revista de Filología Hispánica, XIV, (12), pp. 119-125.

--(1962) Conceptos fundamentales de literatura comparada. Iniciación de la Poesía Modernista. San Juan de Puerto Rico, Asomante.

GonzÁLez, M. P., (1974) “En torno a la iniciación del modernismo", en Homero Castillo (ed.), Estudios críticos sobre el modernismo. Madrid, Gredos.

GutiérRez, J. I., (1992) “Traducción y renovación literaria en el modernismo hispanoamericano", en Livius: Revista de estudios de traducción, 1, pp. 69-84.

Hauser, R. B., (1992) Parnassianism in the Theory and Literature of Spanish American and Spanish Poets. Michigan, University Microfilms International.

Henríquez Ureña, M., (1938) Les influences françaises sur la poésie hispano-américanie. París, Institut des Etudes Américaines, 1938.

--(1941) "Poetas cubanos de expresión francesa", en Revista Iberoamericana, 6, pp. 301-344.

--(1954) Breve historia del modernismo. México, Fondo de Cultura Económica.

Hernández-Miyares, J., (1979) “Julián del Casal: Apuntes sobre la influencia parnasiana en su obra literaria”, en Homenaje a Humberto Piñera. Madrid, Playor, pp. 117-124.

Horta, E., (1908) Bronces y Rosas. La Habana, Imprenta Avisador Comercial.

Lezama Lima, J., (1953) Analecta del reloj. Ensayos. La Habana, Orígenes. 
Llopesa, R., (1989) “Precedentes del modernismo", en Turia. Revista cultural, 12, pp. 15-24.

López, R.; (1986) Barcos que pasan. Edición de Jorge Yglesias, La Habana, Letras Cubanas.

Martí, J., (1946) Obras completas. La Habana, Lex.

--(1973) Obras completas. La Habana, Editorial Nacional de Cuba.

--(1995) Cuentos completos. La Edad de Oro y otros relatos. Barcelona, Anthropos.

--(2004) Obra poética. Edición de J. A. Bueno Álvarez. Madrid, EDAF.

--(2004) Ensayos y crónicas. Edición de J. O. Jiménez. Madrid, Cátedra.

--(2006) Lucía Jerez. Edición de C. J. Morales. Madrid, Cátedra.

Mendive, R. de., (1846) Flores del siglo. La Habana, Tipografía de V. de Torres.

Monner Sans, J. M., (1952) Julián del Casal y el modernismo hispanoamericano, México, El Colegio de México.

Morales, C. J., (1994) La poética de José Martí en su contexto. Madrid, Verbum.

Morán, F., (2010) “Las cartas de Julián del Casal a Gustave Moreau", en Katay (revista digital del Centro de Estudios de Teoría y Crítica Literaria, en http://www.katatay.com.ar/art/12. html), 3-4. Última consulta realizada: 14/08/2012.

Pichardo, F. J., (1908) Voces nómadas. La Habana, Imprenta "La Universal".

PovedA, J. M., (1917) Versos precursores. Manzanillo, Imprenta "El Arte".

--(1948) Proemios de cenáculo. Edición de R. Estenger. La Habana, Ministerio de Educación. 
Prats Torres, G., (1897) “Cosas del día”, en La Ilustración Ibérica, XV, 763, pp. 516-518.

Price, E. C., (1892) Pour l'amour des vers. Paris, Lemerre.

Primo Cano, C., (2010) “La flor y la sierpe. Variaciones orientalistas en torno a Salomé", en Analecta Malacitana (AnMal electrónica), 28, pp. 129-180.

Reyes, A., (1960) Obras Completas. México, Fondo de Cultura Económica.

Salazar, S., (1015) "Rafael María de Mendive", en Cuba Contemporánea, XII, 2, pp. 177-195.

Sellén, A., (1883) Ecos del Sena. La Habana, Tip. de la Viuda de Soler.

Schulman, I. y González, M., (1974) Martí, Darío y el modernismo. Madrid, Gredos.

Suárez León, C., (2001) La sangre y el mármol. Martí, el Parnaso, Baudelaire. La Habana, Centro de Estudios Martianos.

Torres Rioseco, A., (1925) Precursores del Modernismo. Madrid, Calpe.

Valdivia, A., (1879) Ultratumba (pequeño poema). Rimas. Madrid, Imprenta de los Sres. Rojas.

Miguel Ángel Feria

UNIVERSITÉ DE LiMOgES (FrANCIA) 